\title{
Adventures in Remote Learning: Communication Strategies for Active Engagement
}

\section{Dr. Carl W. Luchies, The University of Kansas}

Carl Luchies is an Associate Professor in Mechanical Engineering and a core faculty member in the Bioengineering Graduate Program at the University of Kansas. Dr. Luchies earned his BS, MS and PhD in Mechanical Engineering from the University of Michigan. Dr. Luchies teaches courses in Dynamics, Modeling and Simulation, and Biomechanics. Dr. Luchies utilizes evidence-based, student-centered and active-learning teaching methods in his engineering education program. He conducts education research on the impact of course transformation on student learning. Dr. Luchies also conducts experimental and modeling research focused on the biomechanics and motor control of human movement. He has studied the effects of healthy aging and pathology on human balance, motor control, and movement variability.

\section{Dr. Molly McVey, The University of Kansas}

Dr. Molly A. McVey is a post-doctoral teaching fellow at the University of Kansas School of Engineering where she works with faculty to incorporate evidence-based and student-centered teaching methods, and to research the impacts of changes made to teaching on student learning and success. Dr. McVey earned her Ph.D. in Mechanical Engineering from the University of Kansas. 


\section{Adventures in Transitioning Team-Based Learning from In- Person to Online}

\section{Introduction}

Good communication is fundamental to facilitating active engagement online and to providing an outstanding educational experience. In the world of COVID-19 and the shift from in-person to online learning, good communication between instructor-to-student and student-to-student can be challenging. If a student is reluctant to ask a question in a traditional lecture hall, they may also be reluctant to ask a question in front of their peers in a Zoom meeting. Yet these interactions are crucial to maintaining active student engagement in an online course [1]. During my "check-in" surveys after the emergency move to online teaching due to COVID-19, my students reported a lack of student-to-student interactions. This paper examines methods explored and utilized to improve student-to-student interactions, specifically in the context of the Team-Based Learning (TBL) pedagogy.

\section{Background}

This paper will describe the transition from in-person to fully online instruction for two undergraduate mechanical engineering courses, (1) Statics and Introduction to Mechanics of Materials and (2) Dynamics. The courses had enrollments of 56 and 36 students, respectively, and both courses were taught in an active learning classroom by the primary instructor with support from a graduate teaching assistant and undergraduate teaching fellow (UGTF). The UGTF is primarily responsible for supporting students during in-class problem solving. Both courses were taught using the TBL pedagogy [2]. The four TBL Principles are: (1) groups must be properly formed and managed; (2) students must be made accountable for their individual and team work; (3) team assignments must promote both learning and team development; and (4) students must receive frequent and timely performance feedback.

The structure of TBL utilized in both of these courses consists of: (1) team formation (CATME Team Maker and Peer Evaluations [3, 4], team development), (2) getting students ready (preclass reading/video/PPT lecture, individual and team readiness assurance tests, lecture and example highlights), (3) in-class team active learning, (4) post-class activities (Mastering Engineering homework, structured solutions), and (5) assessment (tests, learning objectives mapped to exam questions, concept inventory, and surveys). This structure in an active learning classroom results in significant instructor-to-student and student-to-student communications. Student-to-student interactions happen organically within several phases of this structure: team readiness assurance tests (concept questions covering the material to be covered during the class session), team development (discussion of attributes of high performing teams), and in-class team active learning (concept questions and problem solving). Instructor-to-student interactions happen organically within the readiness assurance tests, the lecture and example highlights and 
during the in-class active learning. Feedback on progress and performance is provided throughout.

Before the onset of the COVID-19 pandemic, these courses were taught fully in-person and student-to-student and instructor-to-student interactions happened naturally. GroupMe was the primary tool selected by teams for student-to-student communication outside of class.

The emergency shift from in-person to fully online teaching due to COVID-19 in Spring 2020 required that we figure out how to promote these important student-to-student and student-toinstructor interactions. Check-in surveys done shortly after the shift reported a lack of student-tostudent interactions. Therefore, during the Spring 2020 and Fall 2020 semesters, we experimented with a variety of communication and interaction techniques to discover what works, especially for student-to-student communication. This paper describes the process and ultimately the model that we have implemented to recreate the in-person team-based learning experience in an online environment.

\section{Experimentation in Graduate Level Classes}

In the Fall of 2020 I (CL) taught two graduate level courses: a mechanical modeling course and an experimental methods course within the Mechanical Engineering department. These courses are taken by graduate students and upper level undergraduates as an advanced technical elective. Both courses utilize the Absorb-Do-Connect pedagogy [5, 6] with a significant amount of active learning done during class time. Due to COVID-19, both courses started out as HyFlex [7], allowing students to move seamlessly between in-class and online as health issues require, but quickly moved to completely online as the in-person attendance dropped dramatically. Our goal was to provide several communication options at the beginning of the semester as part of the course and then examine what works, especially for student-to-student communication. We experienced no resistance from the students to use the selected tools since they were part of the course design. The lessons learned were utilized in the spring of 2021 when both the Statics and Dynamics undergraduate courses were taught completely online using TBL pedagogy.

\section{Recreating the TBL Classroom Online}

The in-person active learning classroom is a great learning space. The active learning classrooms have tables that seat up to 6 students with an instructor station located somewhere within the room. Consider this the "corporate classroom," i.e. a space where the instructor can interact with all the students verbally via a microphone and visually via information projected to large screens mounted on the room walls and on an LCD screen located at each table. Consider the table of 5-6 students the "team space," i.e. a space where a small group of students can work together, share ideas, ask questions, explain concepts, and show each other their work. One advantage of this active learning classroom design is that during active learning, the instructional team can "surf" the classroom to listen in on discussions, ask guided questions, and address questions and any misconceptions. The second advantage of this design is that it allows switching between the 
"corporate space" and the "team space" organically. This switch takes place often throughout the class time, especially when the teams report out information and feedback is provided in return. The goal was to examine how technology could be used to replicate this in-person TBL environment in the online classroom. Figure 1 shows the recreation of the active learning classroom in the online space using Zoom and Microsoft Teams.
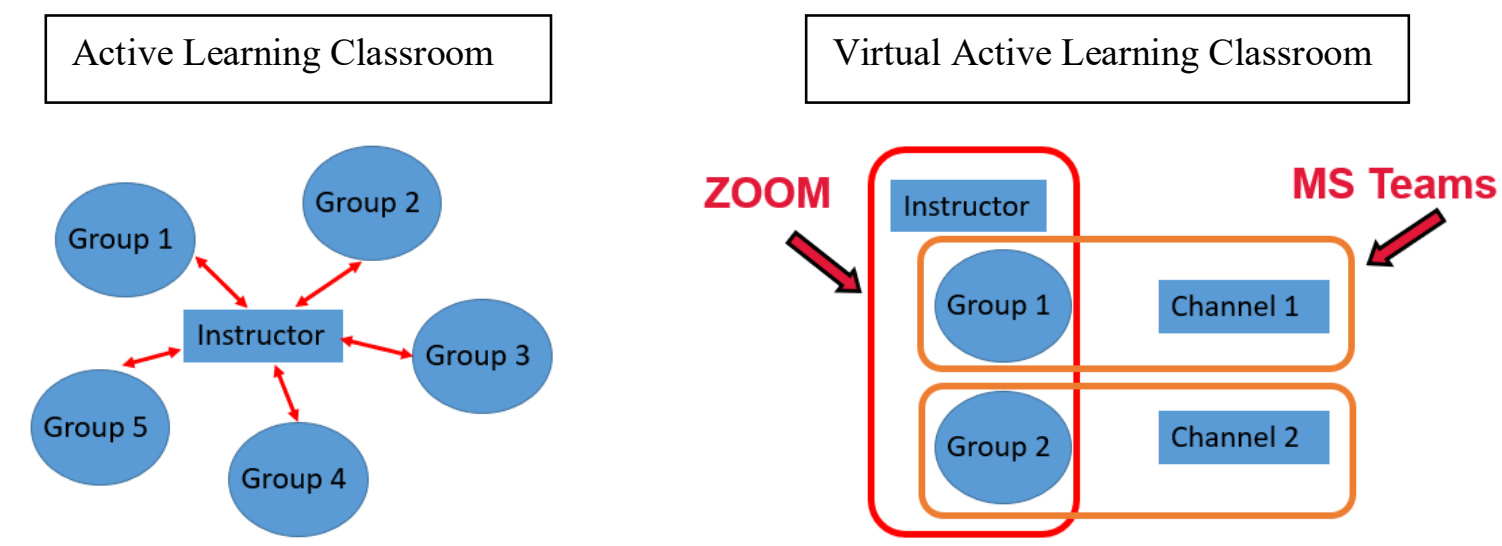

Figure 1. Schematic of how we re-created the active learning classroom in the virtual space.

The online classroom consisted of several important components as shown in Figure 2. First, Zoom was used to replicate the "corporate classroom." For example, the lecture highlights and example problem highlights were provided to all the students at the same time in Zoom. Private breakout rooms were available for one-on-one mentoring during which students could meet privately with an instructional staff member, but this resource was seldom used. Polls were used to provide the instructor with quick feedback from the students. Second, MS Teams was used simultaneously with Zoom to replicate the "team space." Each small group of 5-6 students were assigned to an MS Teams channel. MS Teams was used for the team-readiness assurance quiz, group development, active learning collaboration, questions and answers, discussions, file sharing, white board work, and group mentoring. Within TBL it is very important for the instructor to be able to communicate both orally and visually with all students to provide the justin-time feedback, especially when they are working in their groups within MS Teams.
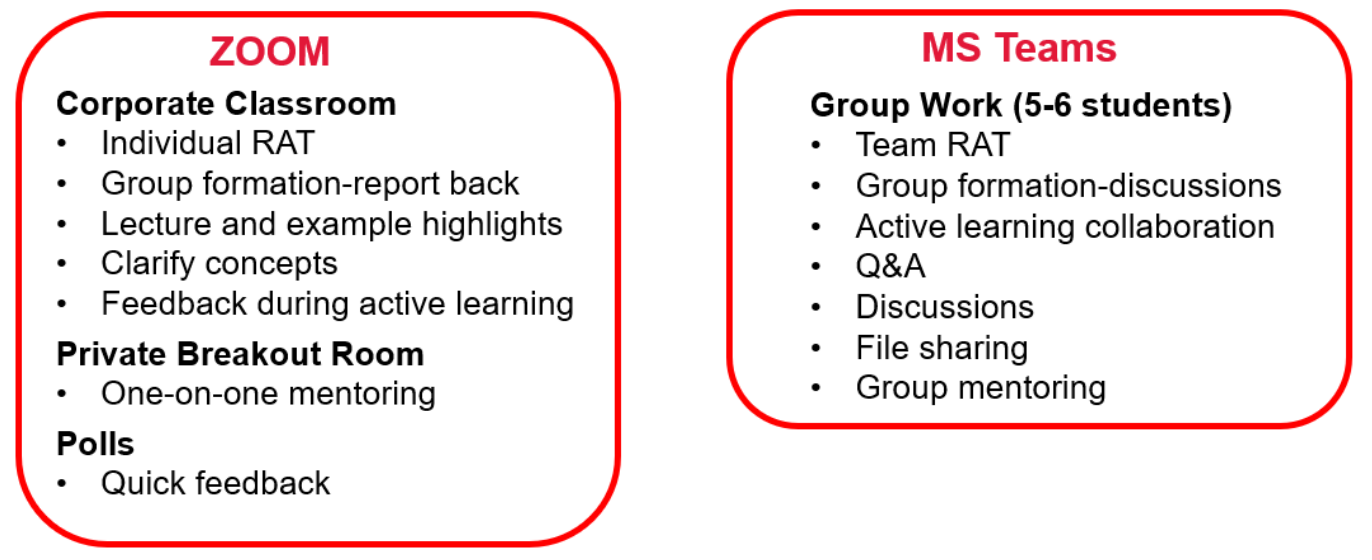

Figure 2. Description of course components in fully online TBL model. 
Unfortunately, this is not currently possible within ZOOM with breakout rooms. In order to communicate with all students after they are in breakout rooms, it is necessary to bring them all back out of breakout rooms for the larger group discussion, then send them back into breakout rooms. The instructional staff were each given membership of all MS Teams channels, which enabled them to "surf" the channels to check in on how each group was doing, ask questions, and answer questions. The only online requirement for the student to move between the "corporate classroom" and their "team space" was to turn on their video and microphone in one space and turn it off in the other space. From the "corporate classroom" (i.e. Zoom) the instructor addressed all the students at one time since the students are not able to mute the instructor's microphone. Thus, when asking the teams to provide feedback (e.g. using I-Clicker Reef), the students could hear the request to "click in", and then also see the results broadcasted on the shared screen in the "corporate classroom." During the group work, the students collaborated in their MS Teams channel to accomplish both concept questions and a more involved problem. The instructor used an ELMO to communicate with all groups by writing on the hardcopy of the group work and sharing the computer screen to which the ELMO was projected using the CAMERA app. The instructor later transitioned to a Wacom One interactive screen, which worked even better than the ELMO. Groups report out on their progress, intermediate calculations and final answers during the group work problems, to which the instructor provides feedback. Students are not allowed to leave the meeting until all members of their team complete the group work problems and fully understand the solution to each problem. To encourage this behavior, extra credit is given on each semester exam if all team members, except for one, score at or above the exam mean. Each student is required to hand in their individual work done on the group problems for grading with the goal of holding the individual accountable for their work done during group work.

The Learning Management System used at this University is BlackBoard (Bb). All materials required for the class are available to the students on $\mathrm{Bb}$. The group work problems were made available the day before class to give the students the opportunity to either obtain a hardcopy and/or load them to their computer for the use of digital ink. The students scanned their work and handed them in digitally via $\mathrm{Bb}$ assignments for grading via rubrics. In $\mathrm{Bb}$ the instructor created a "Weekly Activities" tab, in which the student could select a module, with each module representing a week of class. At the top of each module was a summary of the weekly activities for each day of class: (1) do this before class, (2) do this during class, and (3) this is due at midnight tonight. Any resources needed for that week of class were also provided within the module. This served as an excellent resource for instructor-to-student communication regarding the course activities on a weekly basis.

\section{Results and Discussion}

In order to gauge student opinions about the usefulness of the different platforms utilized for communication and the implementation of the TBL classroom online, a survey was given after the first 3 weeks of class in Spring 2021. The survey was distributed to the 91 students in the two 
courses. Because the two courses (statics: sophomore; dynamics: junior) are close in the level being taught, both are taught using the same TBL pedagogy, and similar trends were seen between the two data sets, we combined the data across the two courses. Sixty-five students responded for a survey response rate of $71 \%$.

In the survey, students were asked to indicate "how useful you are finding each of the following to enhance student-to-student communication," and for each choice ranked it either "very important," "slightly important," or "not important." We asked the students to evaluate each of the following: the main Zoom room, Zoom chat, their MS Teams channel, GroupMe, and email. Students were also asked to indicate "how useful you are finding each of the following to enhance student-to-instructor communication," and again ranked as "very important," "slightly important," or "not important." We asked the students to evaluate each of the following: the main Zoom room, Zoom office hours, Zoom chat, your MS Teams Channel, MS Teams chat, and

\section{Usefulness for Student-Student Interactions} $(\mathrm{N}=65)$

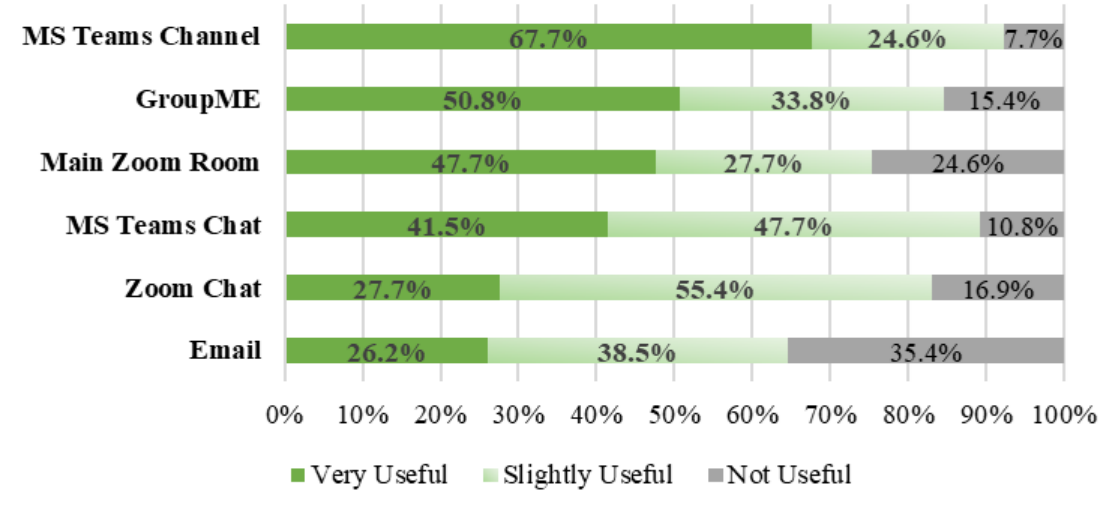

Figure 4. Usefulness for student-student communication. Green= "very useful," Light Green= "slightly useful," Grey= "not useful."

Usefulness for Student-Instructor Interactions $(\mathrm{N}=65)$

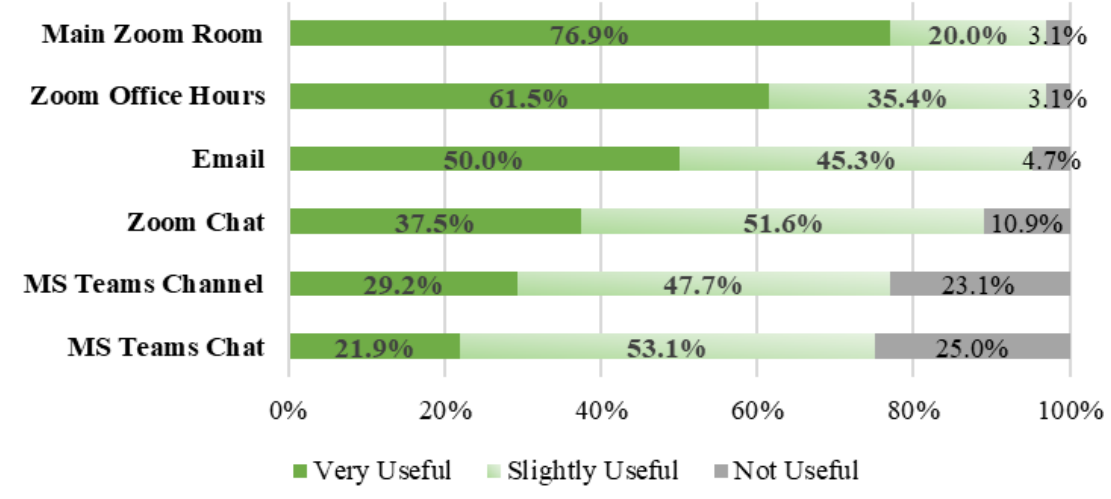

Figure 4. Usefulness for student-instructor communication. Green= "very useful, " Light Green= "slightly useful," Grey= "not useful." 
email. Finally, students were asked to indicate "how important are each of the following resources in supporting your success in this class," and asked to rank either "very important," "slightly important," or "not important." We asked the students to evaluate each of the following resources: the instructor's office hours or direct communication, support offered by the GTA and/or UGTF, attending class online, working with my team members on MS Teams during class, communicating with my team members outside of class time, communicating with students outside of my team, lectures available on Blackboard, the course textbook, and other internet resources. We did not explore student perceived differences is the value of written (e.g. chat) versus visual or audio (video/audio conversation) in these communication approaches.

Figure 3 shows results for the student-to-student communication. Students found the MS Teams channel to be the most useful, with $68 \%$ of respondents ranking it as "very useful," and $25 \%$ of respondents ranking it as "slightly useful." Students also found GroupMe, the main Zoom room, and the MS Teams chat to be somewhat useful for student-student communication. Figure 4 shows results for the student-to-instructor communication. Students found the main Zoom room to be the most useful, with $67 \%$ of respondents ranking it as "very useful," and $20 \%$ of respondents ranking it as "slightly useful." Students also found the Zoom office hours, Email, and the Zoom chat to be somewhat useful for student-to-instructor communication.

Finally, results on what resources students viewed as important to their success in the course are shown in Figure 5. Students found attending class and lectures available on the LMS to be the very important, with $83 \%$ of students responded that attending class online was "very important," and having the lectures available online were viewed as being important as well (75\% responded "very important"). The in-class group work in teams was ranked as being "very important" by $69 \%$ of students, and "slightly important" by $23 \%$ of students.

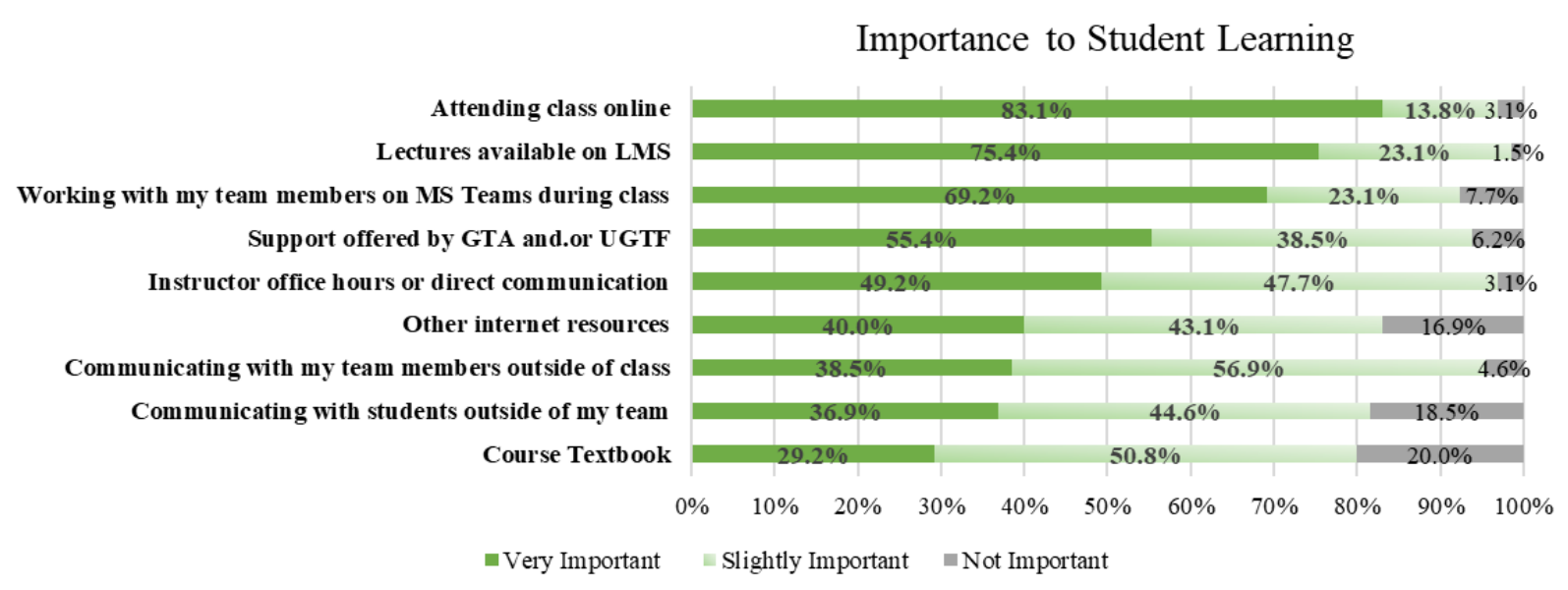

Figure 5. Importance of Resources for Student Learning; Green= "very important," Light Green = "slightly important," Grey= "not important." 
Finally, the survey asked students to rank their level of agreement with the statement "I am very satisfied with the teaching methods the instructor is using for this online course." $45 \%$ of respondents "strongly agreed," 43\% "somewhat agreed," 9\% "neither agreed nor disagreed," $1.5 \%$ "somewhat disagreed," and 1.5\% "strongly disagreed."

These preliminary results indicate that the design of the online model for TBL in these courses seems to be effective in replicating the in-person model. The primary method designed to support student-to-student interaction (MS Teams Channel) was ranked as the most useful by students. The primary method to support student-to-instructor interactions (the main Zoom room) was ranked as the most useful by students. In addition to these primary platforms for interacting, several of the other options for interacting were ranked as being useful as well. In terms of supporting student learning, attending class online was ranked as the most important resource; this implies that the in-class time is useful and supports learning. Finally, over $80 \%$ of respondents strongly or somewhat agreed that they were very satisfied with the teaching methods for the course. We are pleased with the results and feel that we have imitated the in-person experience for an active learning, TBL classroom relatively closely.

\section{Recommendations for Enhancing Student-Student and Student-Teacher Interactions for TBL Online}

Through the experimentation of the Spring 2020 and Fall 2020 semester, we learned many things on our way to developing this model for online Team-Based Learning. Some of our recommendations are included here.

1. We miss the organic and continuous feedback that happens within the in-person classroom. We do not require students to turn on their video during online class time for privacy and equity reasons, resulting in the loss of visual feedback from the students with their video turned off. Body language speaks volumes during active learning group work. Also, there is a significant difference in the feedback gathered during online "surfing" channels in MS Teams compared to in-person "surfing" tables in the classroom.

2. Avoid changing communication platforms during the semester. Prior to the emergency move to online teaching, all of our students in Statics and Dynamics had elected to use GroupMe for student-to-student communications outside of class. When we transitioned from in-person to online, we made MS Teams available to the students, but due to the stress from the abrupt change and the number of new technologies thrown at the students across their courses, we did not require them to utilize MS Teams. The vast majority of students elected to continue to use GroupMe.

3. Communicate and simplify. It is extremely important to be especially transparent about expectations, what is due when, where, etc. Once online, it became clear that the students were overwhelmed with keeping track of their deadlines across their courses. Therefore, we simplified our due dates to be at midnight on each day of class. The students responded very positively to this simple change in assignment due times and dates. We 
also initiated the "Weekly Activities" tab on the Learning Management System, which again was greatly appreciated by the students.

4. Simultaneous use of Zoom and MS Teams works. Using Zoom for the corporate classroom and MS Teams for the team space has worked very well for the authors. We have given several teaching presentations across campus regarding our experience, including the model of simultaneously using Zoom and MS Teams. This has resulted in several colleagues utilizing the model throughout the current semester. We can confidently say that the model works.

5. Instructor-to-student communication can be distracting. We have learned firsthand about a "distraction" issue, which exists in the in-person active learning classroom, but is significantly amplified in the online space. During active learning, students need time to think, focus and work together to develop solutions to the problems provided to them. To enhance learning, just-in-time feedback is provided by the instructor on a regular basis. This can be done without much distraction in the in-person classroom, since the teams can essentially ignore anything being said by the instructor, even if a microphone/sound system is in use. This is very different online. When the instructor speaks in the Zoom corporate classroom, all students hear the instructor loud and clear (keep in mind the student cannot mute the instructor). So loud and clear, in fact, that we have observed that all group work immediately stops when the instructor speaks. Thus, it is very important that the instructor be intentional to minimize the number of interruptions during group work. The instructor must also mute their mic if any conversation takes place not involving the entire class to avoid distracting the entire class. At the same time, it is critical for the instructor to be able to communicate both orally and visually with all students to provide the just-in-time feedback, even when they are working in their groups within MS Teams. Unfortunately, this is not currently possible within ZOOM with breakout rooms.

6. Teaching presence matters. Establishing and maintaining a teaching presence, which is important for student learning, should be woven through the fabric of class time. The structure of TBL provides many opportunities for teaching presence during each class time, without the need for the traditional lecture (in TBL as in flipped classrooms, the lecture is provided on the LMS and viewed before class time). For example, providing brief feedback regarding the readiness assurance quiz questions is an opportunity to provide insight into the concept(s) covered. During team development, which consists of an ice breaker question and a question related to "how to become a highly effective team," each team is required to discuss and then report back to the whole class by providing an example answer for each question. This is a natural time to discuss broader team development ideas. During active learning, "just in time" feedback is provided after the teams have had a chance to work on and struggle with the application of the concepts covered in the group work problems. This is a time that students often ask questions, providing teachable moments used to clarify concepts. 
7. There is value in synchronous teaching in the classroom and online. All Spring 2021 instruction for the two TBL courses described here was done synchronously. Each online session was recorded so that students who were not able to attend could take advantage of the class time discussions. During the Spring 2020 semester we attempted asynchronous group work, which did not work well. Some students reported that group work simply turned into additional homework, done largely on their own. We did not attempt to solve the issues embedded in asynchronous TBL.

8. Show them you care. Brief check-in surveys to see how students are doing is an important instructor-to-student communication. Surveys, which should be done a few weeks into the semester, approximately midsemester, and then at the end of the semester, provide important feedback which can be used to improve the learning opportunity for the students. Not everything works as planned or as intended, so the sooner this can be called to the instructor's attention, the sooner improvements can be implemented. This also communicates to the students that the instructor cares about their learning experience.

\section{Acknowledgements}

We gratefully acknowledge the financial support from the University of Kansas Center for Teaching Excellence for CL as a Teaching Fellow and from the School of Engineering for MM as a Postdoctoral Teaching Fellow.

\section{References}

[1] M. Prince, R. Felder, and R. Brent, "Active Student Engagement in Online STEM Classes: Approaches and Recommendations," Advances in Engineering Education, vol. $8,2020$.

[2] L. K. Michaelsen, A. B. Knight, and L. D. Fink, Team-based learning: A transformative use of small groups. Greenwood publishing group, 2002.

[3] R. A. Layton, M. L. Loughry, M. W. Ohland, and G. D. Ricco, "Design and validation of a web-based system for assigning members to teams using instructor-specified criteria," Advances in Engineering Education, vol. 2, no. 1, pp. 1-28, 2010.

[4] M. W. Ohland et al., "The comprehensive assessment of team member effectiveness: Development of a behaviorally anchored rating scale for self-and peer evaluation," Academy of Management Learning \& Education, vol. 11, no. 4, pp. 609-630, 2012.

[5] W. Horton, E-learning by design. John Wiley \& Sons, 2011.

[6] B. Brett Whorley, M. Camilo Giraldo, M. Arjun Kamath, M McVey, M Patterson, and C Luchies, "Restructuring a Modeling Dynamics Course with Absorb-Do-Connect Learning Units," Conference Proceedings, ASEE Midwest Section Annual Meeting, Wichita, KS, September, 2019.

[7] B. Beatty, "Transitioning to an online world: Using HyFlex courses to bridge the gap," in EdMedia + Innovate Learning, 2007: Association for the Advancement of Computing in Education (AACE), pp. 2701-2706. 